\title{
An investigation into the factor structure of the Ryff Scales of Psychological Well-Being
}

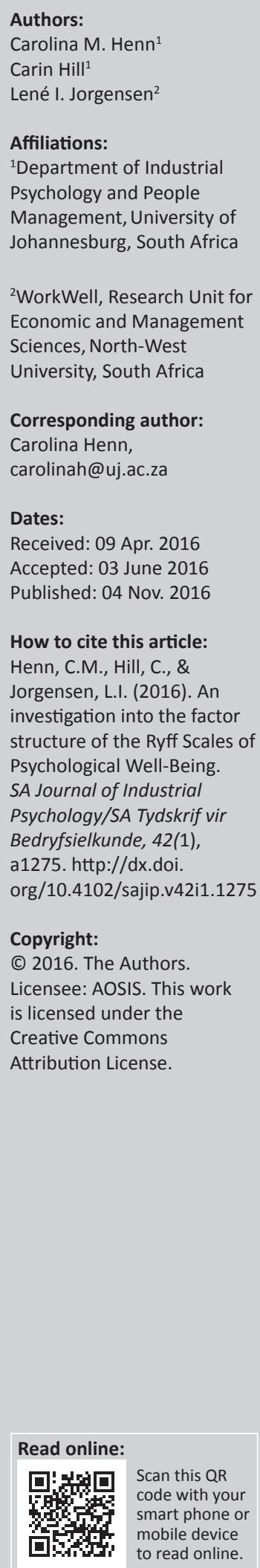

Orientation: South African studies investigating the factor structure of the Ryff Scales of Psychological Well-being (RPWB) are needed to ensure that the instrument is valid and reliable within the South African context.

Research purpose: The objective of this study was to investigate the factor structure of the RPWB within two South African samples.

Motivation for the study: Although a substantial number of studies have been undertaken, results regarding the factor structure of the Ryff Scales of Psychological Well-Being are inconclusive. There is a dearth of information in relation to South African studies examining the scales' factor structure.

Research design, approach and method: A quantitative research approach using a crosssectional field survey design was utilised. An adult working group $(n=202)$ was selected using convenience sampling, and a student group $(n=226)$ was selected by means of purposive non-probability sampling. An Exploratory Factor Analysis and a Confirmatory Factor Analysis were conducted to examine the factor structure.

Main findings: The preferred model was a two-factor model where all the positively worded items were grouped in the first factor and all the negatively worded items were grouped in the second factor.

Practical/managerial implications: The factor structure of the original RPWB was not satisfactorily replicated and remains seemingly unsettled. The utility of negatively worded items should be considered carefully, and alternatives such as mixed response options and phrase completion should be explored. The scales should be used with caution.

Contribution/value-add: The study contributes to the literature concerning the factor structure of the RPWB with an emphasis on the South African context. It contributes to ensuring that researchers and practitioners use a valid and reliable instrument when measuring psychological well-being.

\section{Introduction}

Although there has been a lot of debate concerning the essence of a well-lived life, much of this research has focussed on illness rather than health (Ryff \& Singer, 1998, 2008). Scholars have only recently (see Nelson \& Simmons, 2003) moved towards more holistic models of wellness that include both distress and eustress, thereby making it possible to study both positive and negative aspects of well-being. According to the literature, the principles underlying well-being relate to positive health and are more philosophical than medical in nature; these principals therefore relate to wellness of mind and body and link well-being to engagement in living (Ryff \& Singer, 1998). Ryff developed an extensive model of well-being through building on the works of scholars such as Aristotle, Russel and Rogers (Ryff \& Singer, 2008). According to Ryff and Singer (2008), well-being relates to growth and human fulfilment and has consequences for health.

Carol Ryff investigated psychological well-being in relation to development and growth and developed a model consisting of six core dimensions of psychological well-being (Ryff, 1989c). A measuring instrument, the Ryff Scales of Psychological Well-being (RPWB; Ryff, 1989c), was developed to measure these core dimensions. Although a substantial number of studies have been undertaken using this scale, results regarding the factor structure of the RPWB are inconclusive. Given the growing interest in studying well-being across cultures, Van Dierendonck, Díaz, Rodríguez-Carvajal, Blanco and Moreno-Jiménez (2008) emphasised the importance of gathering more research results on the validity of the RPWB. Therefore, it is important that the 
scale's psychometric properties are given due consideration (Springer, Hauser \& Freese, 2006).

\section{Research purpose and objectives}

This study aims to add to the current body of knowledge by examining the factor structure of the RPWB in a South African sample. Although various South African studies have used the RPWB as a measuring instrument (see Boers, 2014; Botha, 2006; Edwards \& Edwards, 2012; Erhabor \& Ndlovo, 2013; Jones, 2014; Steyn \& Roux, 2009; Vazi et al., 2013; Vercueil, 2010; Victor, 2013), therehavebeen nopublished South African peer-reviewed studies investigating the factor structure of the RPWB. Vazi et al. (2013) and Boers (2014) reported on factor structure in the course of answering other, non-related research questions. Therefore, it is prudent to investigate whether the RPWB is a suitable measuring instrument for use in South Africa.

The present study used the 84-item version of the RPWB based on Burns and Machin's (2009) caution that failure to use longer versions in the validation of the RPWB could potentially result in the loss of a substantial amount of meaningful data because various sample characteristics could influence the factor structure when using a smaller item pool. This study followed a similar approach to that used by Burns and Machin (2009) to validate Ryff's underlying structure. This approach involves first conducting an Exploratory Factor Analysis (EFA) and then using Confirmatory Factor Analysis (CFA) to compare the extracted model to the best fitting models identified in the literature.

\section{Well-being}

Despite an abundance of research, a single agreed-upon definition of well-being remains elusive (cf. Dodge, Paly, Huyton \& Sanders, 2012). There are a number of reasons for the diversity of views concerning well-being, including (1) the various factors that are considered to form part of the well-being construct, such as work and health satisfaction, life satisfaction and levels of enjoyment or depression or anger (Diener, Kesebir \& Lucas, 2008; Henn, 2013); (2) the variety of disciplines investigating well-being, such as psychology, economics, health studies, sociology and anthropology (De Chavez, Backett-Milburn, Parry \& Platt, 2005; Roodt, 1991); and (3) the numerous labels ascribed to the various well-being related factors (Roodt, 1991).

The World Health Organisation (WHO) defined health as 'a state of complete physical, mental and social well-being and not merely the absence of disease or infirmity' (Preamble to the Constitution of the World Health Organisation, p. 100). Well-being literature endorses this definition by focussing on both the absence of negative factors (such as illness) and the presence of positive factors (such as life satisfaction) (Henn, 2013). De Chavez et al. (2005) studied well-being in a variety of disciplines and concluded that although well-being seems to be all-encompassing, in order for its use to be maximised, researchers need to be explicit in their definition, context and measurement of well-being. Huta and Waterman (2014) similarly suggested that the challenges facing the concept of well-being can be addressed by clarifying three classification and terminology considerations, namely: (1) degree of centrality (distinguishing core concepts); (2) category of analysis (stating whether the definition is related to orientations, behaviours, experiences or functioning); and (3) level of trait or state measurement (focussing on whether well-being will be measured as a trait and/or state and whether trait and/or state comparisons will be made).

\section{Psychological well-being}

The present study views well-being as part of the discipline of psychology. De Chavez et al. (2005) found well-being to be a part of but not synonymous with mental and/or psychological health. Van Dierendonck et al. (2008) explained that people have always sought to know what the 'good life' entails and this good life has consequently been directly linked to both well-being and happiness. The degree of centrality for the present study lies within the eudaimonic approach to wellbeing and happiness. According to Deci and Ryan (2008), research regarding well-being can be divided into two approaches, namely hedonic and eudaimonic approaches. Although Kashdan, Biswas-Diener and King (2008) cautioned against differentiating between hedonia and eudaimonia within well-being research stating that the distinction does not translate well to science, Waterman (2008) responded to this caution with a summary of evidence that demonstrates that hedonia and eudaimonia embody '.. inter-related but reliably distinguishable and qualitatively distinct conceptions of happiness making independent contributions to an array of outcome variables' (p. 234).

There is an array of conceptual and operationalisation definitions of eudaimonia and hedonia (see Huta \& Waterman, 2014). Because the present study relates to Ryff's operationalisation of psychological well-being, the operational definitions of hedonia and eudaimonia that underlie Ryff's work are discussed. According to Huta and Waterman (2014), Ryff's conceptual definition of hedonia focusses on subjective experiences of well-being, more precisely in relation to contentment and/or happiness, life satisfaction and positive affect. Eudaimonia, as part of trait psychological well-being, is central to Ryff's empirical research and her conceptual definition references a person who is healthy, well, functions optimally and who can succeed despite life's existential challenges (Huta \& Waterman, 2014; Ryff \& Singer, 2008). Ryff developed a model of psychological well-being that falls within the eudaimonic tradition; this model has 'intuitive appeal' (Burns \& Machin, 2009 , p. 2) and has generated much research interest. Ryff's model of psychological well-being draws widely from various theories, such as the humanistic understandings of Maslow, Allport and Rogers (Ryff \& Keyes, 1995), the utilitarian philosophy of Mill and Russell (Ryff, 2013a) and life-span theories of human development such as Erikson's stages of development (Burns \& Machin, 2009; Ryff \& Keyes, 1995; Triadó, Villar, Solé \& Celdrán, 2007). The final model of psychological well-being proposed by Ryff consists of six factors, which are described below (Ryff, 1989c): 
- Self-acceptance: To have a realistic perception of the self, including both good and bad qualities, and still be able to accept oneself:

- Positive relations with others: To be able to form warm, caring relationships with others; the capability to develop intimacy and to show empathy with others.

- Autonomy: The ability to make one's own decisions without relying on, or waiting for, the approval of others; the ability to measure oneself according to one's own beliefs and not the beliefs of others.

- Environmental mastery: The ability to manage the environment and to mould environments, or to choose environments, which align with one's needs and values:

- Purpose in life: Having goals in life and a sense that one's life has purpose and meaning; living intentionally and with clear direction.

- Personal growth: To continuously grow and develop as a person; working towards optimising one's full potential.

In addition to conceptualising a eudaimonic model of psychological well-being, Ryff and various other researchers identified major correlates regarded as frequent antecedents, consequences or complements of psychological well-being. These include biological correlates, indicating that psychological well-being has positive health benefits in relation to the cardiovascular, neuroendocrine, musculoskeletal and immune systems (Boehm \& Kubzansky, 2012; Ryff \& Singer, 2006; Ryff et al., 2006). Kitayama, Karasawa, Curhan, Ryff and Markus (2010) found a link between culture and wellbeing, while Ryff (2013b) reported on the linkage between family experiences and well-being. Socio-demographic correlates, such as age and socio-economic status, have been noted in the literature to be linked to well-being (Ryff \& Singer, 2008). Psychological well-being has further been indicated to be related to psychological constructs, such as life experiences, emotional intelligence and personality traits (Augusto-Landa, Pulido-Martos \& Lopez-Zafra, 2011; Ryff, 2013b). A strong positive link was also found between educational standing and psychological well-being (referring to personal growth and purpose in life) (see Ryff \& Singer, 2008).

It is possible to identify four categories of analysis in relation to psychological well-being: (1) orientation, which addresses the 'why' of behaviour; (2) behaviour, which investigates the nature of an individual's behaviour; (3) experiences, which focusses on subjective experiences such as affect and cognitive-affective appraisal; and (4) functioning, which examines a person's way of behaving, thinking and functioning that is generally accepted as positive or effective (Huta \& Waterman, 2014). The RPWB model's conceptualisation embodies the functioning category of analysis (see Huta \& Waterman, 2014). Research has shown that psychological well-being as conceptualised by Ryff can be described as an outcome variable as well as a predictor and can be determined through self-reports, observer ratings or performance scores (see Huta \& Waterman, 2014, p. 1432-1434). As an outcome variable, psychological well-being has been shown to be influenced by people's context (Ryff \& Singer, 2008). Steger, Kashdan and Oishi (2008) indicated that psychological well-being has been reported to be an outcome of meaningful activities such as healthy relationships. When psychological needs such as belongingness and purpose in life are met, well-being is experienced (see Steger et al., 2008). The presence of secure relationships where autonomy, relatedness and competence are experienced also seems to aid well-being (Ryan \& Deci, 2001). Finally, Ryff, Magee, Kling and Wing (1999) indicated that wealth has a positive effect on well-being (specifically, self-acceptance, purpose, mastery and growth).

In terms of acting as a predictor, research has found that RPWB strongly predicts multiple levels of well-being (such as environmental mastery, self-acceptance, and purpose in life) in life experiences of parenthood (Ryff et al., 1999). Literature shows that positive relations (a defining element of RPWB) predict physiological functioning and health outcomes (see Ryan \& Deci, 2001) and significant positive relations have been reported between well-being and immune functions (see Ryff, 2013b). Studies have shown that participants with lower cortisol outputs showed higher psychological well-being while eudaimonic well-being has also been linked with insular cortex volume (needed for a variety of higher-order functions) (Ryff, 2013b). The protective influence of purpose of life has been reported in epidemiological studies (risk of cognitive impairment) and various other studies have shown that high psychological well-being predicts health and biological regulation (Ryff, 2013b).

According to Huta and Waterman (2014), a person's degree of eudaimonia (or hedonia) can be determined through either a trait or a state level of measurement. 'Traits' traditionally represent a person's characteristic that stays fairly constant across time and situations; in contrast, the way in which a person adapts to a specific situation is referred to as a 'state' (Hamaker, Nesselroade \& Molenaar, 2007). Ryff (1989c) developed the RPWB to measure the six factors of trait eudaimonic functioning and the scale has subsequently been used extensively (Abbott et al., 2006; Huta \& Waterman, 2014; Springer et al., 2006).

\section{The Ryff Scales of Psychological Well-Being}

The original RPWB questionnaire consisted of 20 items per scale and includes a total of 120 items. Shortened versions of the RPWB containing 84 items (14 items per scale), 54 items (9 per items per scale), 42 items ( 7 items per scale) and 18 items ( 3 items per scale) have also been used in research (Abbott et al., 2006). Van Dierendonck (2004) developed an alternative short version of the RPWB consisting of 39 items. The proliferation of versions is because of the fact that the many validation studies have been unable to generate sufficient indisputable support for Ryff's original a priori sixfactor model (Abbott et al., 2006); additionally shorter versions of the RPWB seemed to increase its structural 
validity because such versions adhere more easily to confirmatory factor analyses assumptions and reduce model misspecification. The various versions reflect attempts to develop a scale that clearly encapsulates Ryff's theoretical model (cf. Abbott et al., 2006). Ryff (1989c) originally assumed a six-factor model based on theory and tested the model in a sample of young, middle-aged and older adults using the 120-item version. Internal consistencies for the six scales ranged from 0.86 to 0.93 . Inter-correlations between the six factors ranged from 0.32 to 0.76 , raising concerns regarding the distinctness of the factors, especially in terms of the high inter-correlations between self-acceptance, environmental mastery, personal growth and purpose in life.

Ryff (2013a) recently presented a multidimensional model of eudaimonic well-being that included an overview of the development of the concept, empirical findings from the last 25 years in terms of how psychological well-being differs with regards to socio-demographic characteristics and in which she linked eudaimonic well-being to biology and health. In her review, Ryff (2013a) referenced five studies that used CFA to confirm that the theory-guided six-factor model is the best fitting model. However, a review of various research studies not mentioned by Ryff (2013a) suggests that the factor structure of the RPWB remains disputed, regardless of the statistical analysis method or number of items used.

Three main statistical analysis methods have been used to examine the psychometric properties of the RPWB. A few studies have used EFA to explore the validity of the RPWB, with results indicating the extraction of between 2 and 15 factors (Burns \& Machin, 2009; Kafka \& Kozma, 2002; Sirigatti et al., 2009; Triadó et al., 2007). Studies using CFA generally test a variety of models including models with the number of first-order factors varying from one to six factors, they also use a variety of method factors, as well as investigating the presence versus absence of second-order factor models (see Abbott et al., 2006; Burns \& Machin, 2009; Sirigatti et al., 2009; Springer \& Hauser, 2006; Van Dierendonck, 2004). Only one study conducted by Abbott, Ploubidis, Huppert, Kuh and Croudace (2010) studied the psychometric properties of the RPWB using Item Response Theory.

Research findings regarding the structure of the RPWB vary. Kafka and Kozma (2001) investigated the factor structure of the 120-item RPWB in a sample of Canadian university students, and an unrestricted factor solution yielded 15 factors. When the factor solution was restricted to six factors, the factors did not load as per Ryff's (1989a) suggested a priori factor structure. Triadó et al. (2007) reported the same finding as Kafka and Kozma in a Spanish translation of the 54-item version. In their study of university students in Japan (utilising a Japanese version of the 84-item measure), Kitamura et al. (2004) found support for the original six-factor model proposed by Ryff. Cheng and Chan (2005) constructed a 28-item version of the RPWB by selecting items that suited the Chinese context and culture and translating these items into Chinese. They also found acceptable fit for a six-factor model of well-being.
A number of studies have investigated the factor structure of the 18-item version of the RPWB. Ryff and Keyes (1995) demonstrated support for the six-factor structure, with a second-order general well-being factor. Inter-item correlations ranged from 0.33 to 0.52 . The highest correlations were between self-acceptance and environmental mastery (0.46) and self-acceptance and positive relations (0.40). Findings by Lindfors, Berntsson and Lundberg (2006) were very similar to those of Ryff and Keyes (1995); they obtained the best model fit for a six-factor structure with a second-order well-being factor. They also reported high inter-item correlations (0.62) between self-acceptance and environmental mastery. Clarke, Marshall, Ryff and Wheaton (2001) found an acceptable solution for a six-factor model in their sample of a geriatric population in Canada. Inter-item correlations were not problematic, but the factor loadings of some items were low. Van Dierendonck (2004) investigated the construct validity of the RPWB and its extension with spiritual well-being and found acceptable fit for a six-factor structure for the 18-item version when making some allowance for the small sample size.

Springer and Hauser (2006) analysed three separate data sets that utilised the 42-, 18- and 12-item versions. Although the six-factor structure showed the best fit in their study, Springer and Hauser (2006) argued that there is insufficient support for the six-factor model proposed by Ryff. They expressed grave concern over the high inter-correlations (0.72-0.97) between factors, with the highest inter-correlations being between environmental mastery and self-acceptance, and purpose in life and self-acceptance. Using the 42 -item version, Abbott et al. (2006) did not find support for a six-factor model. Burns and Machin (2009) found a three-factor model in both a 54-item study and an 84-item study. The first two factors corresponded to the autonomy and positive relations dimensions while the third factor contained the content of the remaining four factors of the Ryff model. In his analysis of the 84-item version, Van Dierendonck (2004) indicated that the comparable fit indices for a six-factor structure for the 84-item version were unacceptably low.

Apart from the apparent problematic and/or inconsistent factor structure of the RPWB, items have posed problems in a number of studies. In studies conducted by Clarke et al. (2001) and Van Dierendonck (2004), some items loaded onto more than one factor. Clarke et al. (2001) dealt with this by allowing items to load onto two factors, and subsequently improved model fit. Van Dierendonck (2004) proposed alternative short scales that differ from the original short version. In a Japanese version of the 84-item version, although support was found for a six-factor model, a number of item loadings did not correspond with Ryff's proposed model. As has been mentioned earlier, the items in the six-factor structures proposed by Kafka and Kozma (2002) and Triadó et al. (2007) also did not load onto the factors as proposed by Ryff.

Various studies have also investigated the presence of methodological artefacts such as creating method factors that isolate between item-covariance orthogonal to the measured constructs (Abbott et al., 2006), correlated measurement error 
(Burns \& Machin, 2009; Clarke et al., 2001; Sirigatti et al., 2013; Springer \& Hauser, 2006), a latent variable representing all the negatively worded items (Ryff \& Keyes, 1995; Springer \& Hauser, 2006), a two-factor model consisting of positively and negatively worded items (Ryff \& Keyes, 1995; Van Dierendonck et al., 2008) and item redundancy (Springer \& Hauser, 2006). Clarke et al. (2001) addressed methodological artefacts by freeing four items to co-vary with alternate constructs and marked a significant increase in model fit in their preferred six-factor model. Abbott et al. (2006) found that the inclusion of ' ... method factors for questions reflecting positive and negative item content, orthogonal to the construct factors and assumed independent of each other, improved model fit by removing nuisance variance' (p. 1). Their preferred RPWB model with acceptable fit consisted of a single second-order factor comprising: (1) the empathy and/or personal growth and/or purpose in life and/or selfacceptance (EGPS) first-order factors, (2) two method factors representing the positively and negatively worded items, and (3) autonomy and positive relations as two distinct firstorder factors. The preferred model identified by Springer and Hauser (2006) consisted of the six-factor theoretical model with a correlated negative method factor and correlated errors between six sets of items. However, model fit was poor. Van Dierendonck et al. (2008) investigated the possibility that the positively and negatively worded items might cluster together and found that although the two method factors produced better fit than Ryff's theoretical model, the preferred model was a six-factor model with a single second-order factor overall. Burns and Machin (2009) included two method variables (in a similar manner to Abbott et al., 2006) as well as correlated error terms. Their results indicated that the sixfactor model that included method factors and positive covariances with Modification Indices $>4$ was the preferred RPWB model. This model produced an excellent fit.

In general, the model fit of the six-factor structure appears to be poor to moderate (Burns \& Machin, 2009; Fernandes, Vasconcelos-Raposo \& Teixeira, 2010; Sirigatti et al., 2009; Van Dierendonck et al., 2008), although a few studies have reported good fit (Abbott et al., 2006; Cheng \& Chan, 2005; Clarke et al., 2001; Kállay \& Rus, 2014; Sirigatti et al., 2013). Springer and Hauser (2006) and Ryff (2013a) concluded that the six-factor model still works better than all the alternate models.

\section{Psychological well-being and the South African context}

As mentioned previously, the RPWB has been utilised in a few South African studies. However, most of these studies did not investigate factor structure. Vazi et al. (2013) performed a factor analysis (FA) on the 24-item version and found a three-factor solution. They named the factors selfevaluation, sense of contentment and sense of competence. Validation of the instrument was not the purpose of their study and they therefore continued by computing an overall score for psychological well-being that excluded autonomy and self-acceptance $(\alpha=0.76)$. Boers (2014) investigated the factor structure of the RPWB by conducting a CFA. She found reasonable fit for the six-factor solution. Because validation of the RPWB was not the main aim of her study, she did not conduct any further investigation into the functioning of the scales. Therefore, it is important to determine whether the RPWB is an accurate operationalisation of Ryff's theoretical model within the South African context.

Despite the use of the RPWB scale in various South African studies, this is the first South African peer-reviewed published study to investigate the factor structure of the RPWB. Therefore, this study supplements the current understanding of the RPWB, specifically within the South African context. According to Van Dierendonck (2004), a well-structured factorial validity study is a good approach for determining the construct validity of a scale, and that is what this study set out to achieve. The research findings regarding the RPWB scale that have been reported in this study underscore the fact that results regarding the factor structure of the RPWB are inconclusive. Although a number of studies have found support for a six-factor structure, high correlations between factors suggest that there may be fewer factors, while the presence of methodological artefacts should also not be ignored.

\section{The present study}

In order to examine the a priori factor structure of the RPWB scale, the analyses were guided by the methods and models identified in the literature. The fits of the following models were considered: firstly, the a priori six-factor model (M1) suggested by Ryff (1989b). Secondly, a one-factor model (M2) will also be included. Many studies investigating the factor structure of the RPWB scale include a one-factor model representing a general well-being factor, although such a model rarely outperforms the other models tested (see Abbott et al., 2006; Cheng \& Chan, 2005; Fernandes et al., 2010; Sirigatti et al., 2009). Thirdly, as suggested by Burns and Machin (2009), the model identified through EFA was used as a unit of analysis within the CFA (M3). Fourthly, a model consisting of a six-factor structure and a second-order latent construct called psychological well-being (M4) has been identified in the literature and was therefore included in this study (Fernandes et al., 2010; Ryff \& Keyes, 1995; Van Dierendonck et al., 2008). The fifth and last theoretical model that was included (M5) consisted of three first-order factors in which the EGPS factors load on one factor, and autonomy and positive relations with others load on the remaining two factors; these three factors then load on a single second-order factor (Burns \& Machin, 2009; Van Dierendonck et al., 2008). Ryff and Keyes (1995) suggested that the inclusion of artefactual models may determine whether a participant answered in a certain manner in order to depict a positive self-image whereby they agree with all the positively worded items and disagree with all the negatively worded items. Therefore, a two-factor model in which all positively formulated items load on the first factor and all negatively formulated items load on the second factor (M6) was also investigated. 


\section{The added value of the present study}

The RPWB has been frequently used within South Africa to measure well-being in various peer-reviewed research articles (see Edwards \& Edwards, 2012; Erhabor \& Ndlovo, 2013; Steyn \& Roux, 2009; Van Schalkwyk \& Wissing, 2010; Vazi et al., 2013) and post-graduate research studies (see Boers, 2014; Botha, 2006; Jones, 2014; Vercueil, 2010; Victor, 2013). Additionally, the instrument is used by practitioners to determine a student or an employee's level of well-being when needed relating to health behaviour and possible workplace interventions. The eudaimonic approach to well-being therapy has been used with success in intervention studies showing significant improvements in mental health, personal growth and well-being (Ryff, 2013b). Literature suggests that flourishing and resilience can be increased by means of well-being interventions (Fava \& Tomba, 2009). By monitoring well-being, business leaders and management are able to identify changes in well-being that could guide policy and improve quality of life (Diener et al., 2008).

Since the instrument is widely used across various research areas and practical settings, the potential value-add of the present study is in assisting future researchers and practitioners in using a valid and reliable instrument within their specific settings.

\section{Research design Research approach}

A quantitative research approach with a cross-sectional field survey design was used. The statistical analyses were conducted using primary data.

\section{Research method}

\section{Research participants}

The research participants $(N=434)$ represented working adults in the Gauteng region of South Africa $(n=187)$ as well as students at a tertiary institution in the north-west region of South Africa $(n=247)$. The working adults represented corporates in financial services, information technology, legal, logistics and motor industries. In terms of gender, the sample consisted of 135 (31\%) male and 257 (59\%) female participants; $10 \%$ of the sample did not indicate their gender. The ages of the participants ranged between 18 and 68 years, mostly distributed between 19 and 43 years (77\%). The racial distribution of the sample was as follows: 12\% African, $7 \%$ Coloured, $4 \%$ Indian and 69\% White (9\% did not indicate their race).

\section{Measuring instrument}

Ryff Scales of Psychological Well-being: The participants' psychological well-being was assessed using the RPWB. Ryff (1989b) developed the 84-item scale to measure six identified components of well-being: (1) self-acceptance (e.g., 'When I look at the story of my life, I am pleased with how things have turned out'); (2) positive relations with others (e.g., 'People would describe me as a giving person, willing to share my time with others'); (3) autonomy (e.g., 'My decisions are not usually influenced by what everyone else is doing'); (4) environmental mastery (e.g., 'I am quite good at managing the many responsibilities of my daily life'); (5) purpose in life (e.g., 'I used to set goals for myself, but that now seems like a waste of time'); and (6) personal growth (e.g., 'I gave up trying to make big improvements or changes in my life a long time ago'). Responses for the scale are presented on a six-point agreement scale that ranges from 1 (strongly disagree) to 6 (strongly agree). Van Dierendonck (2004) found an acceptable internal consistency for the 84-item version in a Dutch sample, with alphas ranging between 0.77 and 0.90. A South African study found Cronbach's alpha coefficients for the six scales ranging between 0.83 and 0.91 (Davidson, 2006).

\section{Research procedure}

All participants were at least 18 years old and were informed that completion of the questionnaire was voluntary. The rationale of the study was explained to all participants, and they were also assured of the confidentiality of the data. Informed consent was obtained from individual participants. A sample of industrial and organisational psychology students from a higher education institute in South Africa was selected by means of a purposive, non-probability sampling method. Permission for the inclusion of students in this study was granted by the relevant university's ethical clearance committee, and an ethical clearance number was awarded to the project. The students were enrolled for a fulltime degree in the field of industrial and organisational psychology for the period 2012-2014. All the participants were requested to complete either an online version or a paper-and-pencil version of the questionnaire.

\section{Statistical analysis}

In order to analyse the data, SPSS Version 22 and Amos Graphics were used (IBM Corp, 2013). Data were screened for accuracy, missing values and outliers. Eight missing values were replaced with the mean. The initial data set contained 498 cases, but 64 outlier cases were deleted resulting in a final sample size of 434 cases. According to the review of literature regarding sample size by Williams, Brown and Onsman (2012), more than 300 cases are seen as good for FA. The descriptive statistics of the scale (means, standard deviations, skewness and kurtosis coefficients) were checked to determine the normal distribution of the data.

Next, principal component analysis was used to determine which linear components existed within the data set and to determine 'how a particular variable might contribute to that component' (Field, 2005, p. 631). First, the Kaiser-Meyer-Olkin measure of sampling adequacy (KMO) and Bartlett's test of sphericity were inspected to determine whether the respondent data would be suitable for FA. If the KMO revealed a good pattern of correlations (Field, 2005) and the Bartlett's test of sphericity proved to be significant, the respondent data were 
deemed appropriate. According to Williams et al. (2012), the $\mathrm{KMO}$ index is recommended when the cases to variable ratio is less than 1:5 (as in the present study). To determine the number of factors to retain, a few considerations were investigated as suggested by Henson and Roberts (2006) and Williams et al. (2012). Kaiser's criterion suggests retaining components that have an eigenvalue of 1 or more (Pallant, 2011), and although fixed thresholds now exist, Williams et al. (2012) found that within the humanities, explained variance of between $50 \%$ and $60 \%$ is commonly reported. Henson and Roberts (2006) also suggested that the explained variance for the first factor not retained should also be reported. Field (2005) recommended that the scree plot be used to determine how many factors to retain and that the analysis should then be rerun specifying the number of factors to extract using FA. Parallel analysis of the data was also conducted to assist in determining the number of factors to retain.

Using a maximum likelihood FA with an oblique rotation method (direct oblimin), the identified factors were then extracted. An oblique rotation was chosen because the extracted factors should, according to theory, correlate (see Field, 2005). Next, the pattern matrix was examined in order to establish whether the various factors had factor loadings $\geq 0.35$, because according to Clark and Watson (1995), loadings less than 0.35 are considered weak. To investigate the internal consistency of the various factors, the Cronbach's alpha coefficients for each of the factors were computed.

In order to evaluate the fit of the various RPWB models, CFA was used to compare the fit statistics of the competing models. The models that were investigated are listed below:

- M1: 'a priori' six-factor model

- M2: one-factor model

- M3: EFA model

- M4: six-factor first-order, second-order model

- M5: three-factor first-order (EGPS, autonomy, positive relations), second-order model

- M6: two-factor model (positive, negative)

Maximum Likelihood Estimation was used to estimate the coefficients and the goodness-of-fit indices that were assessed included chi-square statistics (non-significant $\chi^{2}, \mathrm{CMIN} /$ $\mathrm{DF}<5)$, the Root Mean Square Error of Approximation (values close to 0.06 or below $=$ good fit), the comparative fit index and the Tucker-Lewis index (values close to 0.95 and greater $=$ good fit), as well as the Akaike Information Criterion (AIC), the Bayesian Information Criterion (the smallest value is preferred) and the Expected Cross-Validation Index (ECVI) which were used to compare the non-nested models (models with the lowest AIC and ECVI reveals better fit). Benchmarks were obtained from Brown (2006).

\section{Results}

The descriptive statistics including means, standard deviations, skewness and kurtosis coefficients of the RPWB scale were investigated and the normal distribution of the data was confirmed (see Table 1).
The KMO yielded a value of 0.98 and the Bartlett's test of sphericity proved to be significant. A total of 10 components had eigenvalues greater than 1 ; the scree plot suggested five factors should be retained, while the parallel analysis suggested four (see Figure 1).

TABLE 1: Descriptive statistics for the Ryff Scales of Psychological WellBeing.

\begin{tabular}{|c|c|c|c|c|}
\hline Item & Mean & Standard deviation & Skewness & Kurtosis \\
\hline Q1PRp & 3.34 & 1.65 & 0.13 & -1.27 \\
\hline Q1AUn & 3.73 & 1.51 & -0.11 & -0.96 \\
\hline Q1EMp & 3.56 & 1.60 & 0.05 & -1.23 \\
\hline Q1PGn & 3.64 & 1.93 & -0.10 & -1.54 \\
\hline Q1PLp & 3.31 & 1.84 & 0.17 & -1.44 \\
\hline Q1Sap & 3.29 & 1.77 & 0.20 & -1.37 \\
\hline Q2PRn & 3.46 & 1.65 & 0.05 & -1.22 \\
\hline Q2AUp & 3.41 & 1.64 & 0.09 & -1.20 \\
\hline Q2EMn & 3.44 & 1.41 & -0.02 & -0.94 \\
\hline Q2PGp & 3.39 & 1.87 & 0.06 & -1.52 \\
\hline Q2PLn & 3.36 & 1.66 & 0.09 & -1.23 \\
\hline Q2Sap & 3.56 & 1.70 & 0.05 & -1.33 \\
\hline Q3PRn & 3.45 & 1.73 & 0.03 & -1.30 \\
\hline Q3AUp & 3.53 & 1.60 & -0.01 & -1.14 \\
\hline Q3EMn & 3.55 & 1.80 & -0.04 & -1.39 \\
\hline Q3PGp & 3.57 & 1.70 & -0.12 & -1.28 \\
\hline Q3PLn & 3.58 & 1.58 & -0.07 & -1.18 \\
\hline Q3San & 3.52 & 1.63 & -0.03 & -1.18 \\
\hline Q4PRp & 3.38 & 1.93 & 0.09 & -1.56 \\
\hline Q4AUn & 3.35 & 1.58 & 0.07 & -1.10 \\
\hline Q4EMp & 3.53 & 1.74 & 0.07 & -1.39 \\
\hline Q4PGn & 3.24 & 1.59 & 0.14 & -1.17 \\
\hline Q4PLp & 3.44 & 1.78 & 0.06 & -1.42 \\
\hline Q4San & 3.68 & 1.52 & -0.10 & -1.01 \\
\hline Q5PRp & 3.34 & 2.08 & 0.10 & -1.71 \\
\hline Q5AUp & 3.39 & 1.96 & 0.11 & -1.56 \\
\hline Q5EMn & 3.37 & 1.41 & 0.07 & -0.85 \\
\hline Q5PGp & 3.51 & 1.84 & 0.01 & -1.45 \\
\hline Q5PLn & 3.46 & 1.63 & -0.05 & -1.18 \\
\hline Q5Sap & 3.42 & 1.72 & 0.05 & -1.42 \\
\hline Q6PRn & 3.50 & 1.75 & -0.02 & -1.36 \\
\hline Q6AUn & 3.52 & 1.56 & 0.00 & -1.11 \\
\hline Q6EMp & 3.42 & 1.79 & 0.18 & -1.37 \\
\hline Q6PGn & 3.58 & 1.91 & -0.09 & -1.51 \\
\hline Q6PLn & 3.59 & 1.87 & -0.02 & -1.49 \\
\hline Q6Sap & 3.29 & 1.83 & 0.19 & -1.45 \\
\hline Q7PRp & 3.27 & 1.69 & 0.20 & -1.25 \\
\hline Q7AUp & 3.53 & 1.69 & -0.11 & -1.28 \\
\hline Q7EMp & 3.44 & 1.70 & 0.10 & -1.28 \\
\hline Q7PGp & 3.53 & 2.06 & 0.01 & -1.67 \\
\hline Q7PLn & 3.46 & 1.75 & -0.01 & -1.27 \\
\hline Q7San & 3.59 & 1.88 & -0.07 & -1.49 \\
\hline Q8PRn & 3.52 & 1.73 & -0.04 & -1.33 \\
\hline Q8AUn & 3.50 & 1.92 & -0.01 & -1.54 \\
\hline Q8EMn & 3.43 & 1.57 & 0.03 & -1.09 \\
\hline Q8PGp & 3.44 & 2.00 & 0.07 & -1.63 \\
\hline Q8PLp & 3.49 & 1.81 & 0.10 & -1.43 \\
\hline Q8Sap & 3.41 & 1.95 & 0.11 & -1.60 \\
\hline Q9PRp & 3.35 & 1.79 & 0.13 & -1.40 \\
\hline Q9AUp & 3.59 & 1.65 & -0.03 & -1.22 \\
\hline Q9EMp & 3.60 & 1.58 & -0.07 & -1.14 \\
\hline Q9PGp & 3.47 & 1.84 & 0.06 & -1.50 \\
\hline Q9PLp & 3.44 & 1.67 & 0.09 & -1.33 \\
\hline Q9San & 3.38 & 1.61 & 0.07 & -1.16 \\
\hline
\end{tabular}


TABLE 1 (Continues...): Descriptive statistics for the Ryff Scales of Psychological Well-Being.

\begin{tabular}{lcccc}
\hline Item & Mean & Standard deviation & Skewness & Kurtosis \\
\hline Q10PRn & 3.75 & 1.74 & -0.25 & -1.28 \\
Q10AUn & 3.56 & 1.73 & -0.08 & -1.32 \\
Q10EMp & 3.53 & 1.68 & -0.02 & -1.32 \\
Q10PGn & 3.35 & 1.56 & 0.03 & -1.10 \\
Q10PLp & 3.51 & 1.74 & 0.07 & -1.36 \\
Q10San & 3.48 & 1.62 & -0.04 & -1.18 \\
Q11PRn & 3.44 & 1.68 & 0.04 & -1.29 \\
Q11AUn & 3.25 & 1.46 & 0.19 & -0.91 \\
Q11EMn & 3.40 & 1.59 & 0.07 & -1.14 \\
Q11PGp & 3.45 & 1.96 & 0.06 & -1.60 \\
Q11PLn & 3.50 & 1.86 & 0.01 & -1.47 \\
Q11San & 3.52 & 1.76 & -0.08 & -1.32 \\
Q12PRp & 3.33 & 1.92 & 0.15 & -1.54 \\
Q12AUp & 3.42 & 1.79 & 0.08 & -1.41 \\
Q12EMp & 3.35 & 1.51 & 0.20 & -1.08 \\
Q12PGp & 3.37 & 1.84 & 0.12 & -1.47 \\
Q12PLp & 3.40 & 1.66 & 0.05 & -1.26 \\
Q12Sap & 3.21 & 1.74 & 0.28 & -1.25 \\
Q13PRn & 3.42 & 1.62 & 0.02 & -1.19 \\
Q13AUn & 3.39 & 1.58 & 0.13 & -1.08 \\
Q13EMn & 3.44 & 1.63 & 0.01 & -1.17 \\
Q13PGn & 3.47 & 1.81 & -0.02 & -1.41 \\
Q13PLp & 3.45 & 1.73 & 0.10 & -1.34 \\
Q13Sap & 3.43 & 1.63 & 0.16 & -1.20 \\
Q14PRp & 3.26 & 1.72 & 0.11 & -1.33 \\
Q14AUp & 3.41 & 1.83 & 0.12 & -1.46 \\
Q14EMp & 3.47 & 1.65 & 0.06 & -1.25 \\
Q14PGn & 3.55 & 1.82 & -0.08 & -1.41 \\
Q14PLn & 3.69 & 1.79 & -1.15 & -1.37 \\
Q14San & 3.43 & 1.72 & & -1.28 \\
\hline & & & 06 & \\
\hline
\end{tabular}

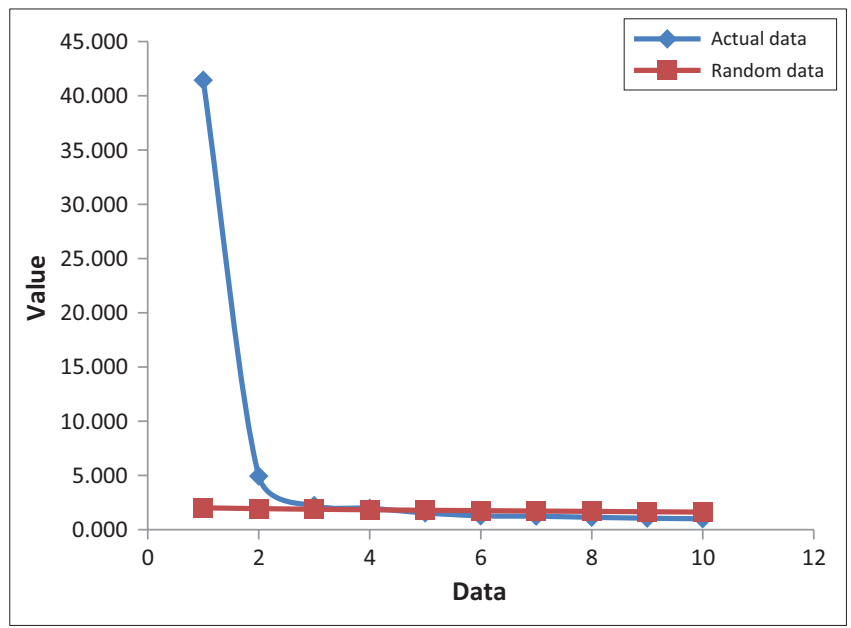

FIGURE 1: Scree and parallel analysis plot.

After further investigation, a five-factor solution seemed to best represent the data. The results for the five-factor solution that was extracted using a maximum likelihood FA with an oblique rotation method are presented in Table 2.

The five factors were well represented with factor loadings $\geq 0.35$; however, 11 items were excluded from further analyses due to weak or double-factor loadings. The communalities ranged between 0.45 (average) and 0.88 (high). The factors were labelled as follows: general psychological well-being (47 items, $\alpha=0.98$ ); interpersonal dependence (7 items,
TABLE 2: Maximum likelihood analysis with direct oblimin rotation pattern matrix for the Ryff Scales of Psychological Well-Being.

\begin{tabular}{|c|c|c|c|c|c|c|}
\hline Factors & F1 & F2 & F3 & F4 & F5 & $h^{2}$ \\
\hline Q8SAp & 0.90 & 0.05 & 0.00 & -0.06 & -0.08 & 0.88 \\
\hline Q6SAp & 0.86 & -0.01 & 0.05 & 0.03 & -0.11 & 0.81 \\
\hline Q5SAp & 0.85 & -0.08 & 0.01 & -0.02 & 0.00 & 0.78 \\
\hline Q12PRp & 0.84 & 0.02 & -0.02 & -0.23 & 0.16 & 0.74 \\
\hline Q8PGp & 0.83 & 0.02 & -0.15 & 0.01 & -0.05 & 0.86 \\
\hline Q9PRp & 0.82 & 0.06 & -0.09 & -0.06 & -0.02 & 0.77 \\
\hline Q5PRp & 0.82 & 0.09 & -0.23 & -0.02 & 0.02 & 0.85 \\
\hline Q9PGp & 0.82 & 0.02 & -0.10 & 0.01 & -0.12 & 0.87 \\
\hline Q4EMp & 0.82 & -0.06 & 0.09 & 0.03 & -0.09 & 0.74 \\
\hline Q13PLp & 0.81 & 0.05 & 0.08 & -0.05 & -0.14 & 0.77 \\
\hline Q14PRp & 0.81 & 0.12 & -0.08 & -0.27 & 0.16 & 0.74 \\
\hline Q9EMp & 0.81 & -0.11 & 0.21 & 0.08 & -0.11 & 0.71 \\
\hline Q7PRp & 0.81 & 0.09 & -0.01 & -0.30 & 0.14 & 0.75 \\
\hline Q12PGp & 0.80 & -0.01 & -0.14 & 0.01 & -0.10 & 0.88 \\
\hline Q13SAp & 0.80 & -0.05 & 0.18 & -0.04 & -0.03 & 0.68 \\
\hline Q9AUp & 0.80 & -0.19 & -0.11 & 0.02 & 0.08 & 0.81 \\
\hline Q2PGp & 0.80 & 0.10 & -0.20 & 0.03 & -0.02 & 0.79 \\
\hline Q4PRp & 0.80 & 0.11 & -0.19 & -0.05 & -0.01 & 0.81 \\
\hline Q5AUp & 0.79 & -0.13 & -0.13 & 0.10 & 0.02 & 0.78 \\
\hline Q14AUp & 0.79 & -0.15 & -0.13 & 0.06 & 0.10 & 0.74 \\
\hline Q1PRp & 0.78 & 0.14 & -0.07 & -0.11 & 0.04 & 0.65 \\
\hline Q8PLp & 0.78 & 0.06 & -0.05 & 0.10 & -0.23 & 0.83 \\
\hline Q7PGp & 0.77 & 0.00 & -0.24 & 0.02 & -0.04 & 0.86 \\
\hline Q11PGp & 0.77 & 0.07 & -0.18 & -0.03 & -0.07 & 0.82 \\
\hline Q7EMp & 0.77 & -0.05 & 0.14 & 0.09 & -0.15 & 0.67 \\
\hline Q9PLp & 0.76 & 0.02 & 0.07 & 0.03 & -0.26 & 0.79 \\
\hline Q1SAp & 0.76 & 0.03 & 0.11 & -0.04 & -0.21 & 0.75 \\
\hline Q6EMp & 0.76 & -0.06 & 0.01 & 0.07 & -0.11 & 0.71 \\
\hline Q12EMp & 0.75 & -0.02 & 0.05 & -0.22 & -0.01 & 0.71 \\
\hline Q12PLp & 0.75 & 0.00 & 0.05 & 0.00 & -0.20 & 0.74 \\
\hline Q14EMp & 0.75 & -0.09 & 0.15 & -0.06 & -0.12 & 0.68 \\
\hline Q10EMp & 0.75 & 0.03 & 0.03 & 0.01 & -0.12 & 0.66 \\
\hline Q12SAp & 0.74 & 0.00 & 0.03 & -0.10 & 0.01 & 0.63 \\
\hline Q2SAp & 0.73 & -0.10 & 0.09 & -0.13 & -0.12 & 0.76 \\
\hline Q4PLp & 0.73 & 0.01 & 0.02 & 0.08 & -0.28 & 0.78 \\
\hline Q5PGp & 0.72 & 0.00 & -0.29 & -0.03 & 0.03 & 0.82 \\
\hline Q1PLp & 0.68 & 0.01 & -0.13 & 0.03 & -0.17 & 0.74 \\
\hline Q1EMp & 0.67 & -0.08 & -0.03 & 0.00 & -0.09 & 0.64 \\
\hline Q2AUp & 0.66 & -0.18 & -0.14 & 0.08 & 0.14 & 0.57 \\
\hline Q3PGp & 0.63 & -0.05 & -0.22 & -0.07 & 0.06 & 0.71 \\
\hline Q12AUp & 0.58 & -0.18 & -0.11 & 0.12 & 0.06 & 0.48 \\
\hline Q10PLp & 0.58 & -0.04 & -0.12 & 0.05 & -0.15 & 0.60 \\
\hline Q3AUp & 0.49 & -0.33 & -0.01 & 0.28 & 0.04 & 0.51 \\
\hline Q8AUn & -0.48 & 0.26 & 0.22 & 0.04 & 0.09 & 0.71 \\
\hline Q3EMn & -0.41 & 0.01 & 0.20 & 0.33 & 0.11 & 0.66 \\
\hline Q11SAn & -0.37 & 0.12 & -0.07 & 0.24 & 0.34 & 0.63 \\
\hline Q13PGn & -0.36 & 0.06 & 0.27 & 0.10 & 0.34 & 0.69 \\
\hline Q7AUp & 0.32 & -0.21 & -0.08 & 0.19 & 0.03 & 0.59 \\
\hline Q4AUn & -0.07 & 0.65 & 0.00 & 0.04 & -0.03 & 0.67 \\
\hline Q11AUn & 0.00 & 0.57 & 0.28 & -0.04 & 0.06 & 0.60 \\
\hline Q13AUn & -0.06 & 0.52 & 0.14 & 0.10 & 0.11 & 0.65 \\
\hline Q5EMn & 0.21 & 0.45 & -0.12 & 0.16 & 0.10 & 0.64 \\
\hline Q1AUn & -0.02 & 0.42 & 0.07 & -0.01 & -0.01 & 0.57 \\
\hline Q9SAn & -0.17 & 0.39 & 0.07 & 0.13 & 0.01 & 0.59 \\
\hline Q6AUn & -0.17 & 0.37 & 0.12 & 0.07 & 0.05 & 0.45 \\
\hline Q8EMn & 0.00 & 0.27 & -0.18 & 0.25 & 0.23 & 0.76 \\
\hline Q2EMn & -0.12 & 0.22 & -0.03 & 0.20 & 0.19 & 0.57 \\
\hline Q4PGn & -0.11 & 0.03 & 0.49 & 0.07 & 0.07 & 0.62 \\
\hline Q1PGn & -0.36 & 0.04 & 0.45 & 0.05 & 0.12 & 0.66 \\
\hline Q11PLn & -0.23 & 0.08 & 0.45 & -0.04 & 0.26 & 0.64 \\
\hline Q14PGn & -0.03 & 0.19 & 0.44 & -0.04 & 0.18 & 0.52 \\
\hline
\end{tabular}

Table 2 continues $\rightarrow$ 
TABLE 2 (Continues...): Maximum likelihood analysis with direct oblimin rotation pattern matrix for the Ryff Scales of Psychological Well-Being.

\begin{tabular}{|c|c|c|c|c|c|c|}
\hline Factors & $\mathrm{F} 1$ & F2 & F3 & F4 & F5 & h2 \\
\hline Q10PGn & 0.10 & 0.13 & 0.42 & 0.20 & 0.08 & 0.66 \\
\hline Q10AUn & -0.29 & 0.30 & 0.31 & 0.18 & 0.03 & 0.63 \\
\hline Q3PRn & -0.15 & 0.01 & 0.01 & 0.58 & 0.05 & 0.61 \\
\hline Q8PRn & -0.11 & 0.09 & -0.07 & 0.57 & 0.15 & 0.58 \\
\hline Q11PRn & -0.17 & 0.20 & 0.12 & 0.50 & 0.11 & 0.63 \\
\hline Q10PRn & -0.25 & 0.01 & 0.21 & 0.46 & 0.10 & 0.65 \\
\hline Q6PRn & -0.31 & 0.03 & 0.11 & 0.44 & 0.18 & 0.61 \\
\hline Q13PRn & 0.07 & 0.13 & 0.11 & 0.43 & -0.02 & 0.72 \\
\hline Q2PRn & -0.16 & 0.07 & 0.18 & 0.37 & 0.03 & 0.59 \\
\hline Q4SAn & 0.11 & 0.30 & -0.18 & 0.36 & 0.06 & 0.54 \\
\hline Q10SAn & -0.19 & 0.30 & -0.05 & 0.33 & 0.14 & 0.58 \\
\hline Q13EMn & -0.26 & 0.25 & 0.01 & 0.26 & 0.23 & 0.64 \\
\hline Q7PLn & -0.21 & 0.03 & 0.17 & 0.12 & 0.52 & 0.66 \\
\hline Q6PLn & -0.29 & 0.07 & 0.22 & 0.08 & 0.47 & 0.72 \\
\hline Q7SAn & -0.40 & -0.01 & 0.08 & 0.21 & 0.43 & 0.77 \\
\hline Q3SAn & -0.11 & 0.24 & -0.01 & 0.12 & 0.42 & 0.68 \\
\hline Q14SAn & -0.13 & 0.23 & 0.20 & 0.15 & 0.40 & 0.66 \\
\hline Q5PLn & -0.24 & -0.04 & 0.12 & 0.14 & 0.39 & 0.58 \\
\hline Q3PLn & -0.12 & 0.08 & 0.27 & -0.03 & 0.39 & 0.67 \\
\hline Q11EMn & -0.08 & 0.24 & 0.05 & 0.18 & 0.37 & 0.63 \\
\hline Q14PLn & -0.33 & 0.17 & 0.14 & 0.12 & 0.35 & 0.70 \\
\hline Q6PGn & -0.30 & -0.02 & 0.29 & 0.15 & 0.34 & 0.65 \\
\hline Q2PLn & -0.15 & -0.03 & 0.25 & -0.08 & 0.31 & 0.63 \\
\hline $\begin{array}{l}\text { \% Variance } \\
\text { explained }\end{array}$ & 49.34 & 5.89 & 2.66 & 2.35 & 1.84 & - \\
\hline
\end{tabular}

Note: Values in bold denote loadings $\geq 0.35$

TABLE 3: Summary of goodness-of-fit statistics for the various Ryff Scales of Psychological Well-Being models tested.

\begin{tabular}{lccccccccc}
\hline Model & $\chi 2$ & $d f$ & $\chi 2 / d f$ & RMSEA & CFI & TLI & AIC & BIC & ECVI \\
\hline M1 & 9973.36 & 3387 & 2.95 & 0.07 & 0.81 & 0.80 & 10339.36 & 11084.73 & 23.88 \\
M2 & 10761.65 & 3402 & 3.16 & 0.07 & 0.78 & 0.78 & 11097.65 & 11781.92 & 25.63 \\
M3 & 11262.03 & 3403 & 3.31 & 0.07 & 0.77 & 0.76 & 11596.03 & 12276.23 & 26.78 \\
M4 & 10086.78 & 3396 & 2.97 & 0.07 & 0.80 & 0.80 & 10434.78 & 11143.49 & 24.10 \\
M5 & 10426.21 & 3399 & 3.07 & 0.07 & 0.79 & 0.79 & 10768.21 & 11464.70 & 24.89 \\
M6 & 8961.64 & 3401 & 2.64 & 0.06 & 0.84 & 0.83 & 9299.64 & 9987.99 & 21.48 \\
\hline
\end{tabular}

M1, a priori six-factor model; M2, one-factor model; M3, Exploratory Factor Analysis model; M4 six-factor first-order, second-order model; M5, three-factor first-order (empathy and/or personal growth and/or purpose in life and/or self-acceptance, autonomy, positive relations), secondorder model; M6, two-factor model (positive, negative); RMSEA, Root Mean Square Error of Approximation; CFI, comparative fit index; TLI, Tucker-Lewis index; AIC, Akaike Information Criterion; BIC, Bayesian Information Criterion; ECVI, Expected Cross-Validation Index.

Note: All chi-square statistics were significant $(p<0.001)$

$\alpha=0.77$ ); obstinate (4 items, $\alpha=0.72$ ); sense of loneliness ( 8 items, $\alpha=0.83$ ); and low motivation ( 7 items, $\alpha=0.87$ ). The percentage variance explained by the five extracted factors was $62 \%$, while the sixth factor that was not extracted explained a further $2 \%$ of the total variance.

The results for the CFA analyses of the suggested RPWB models are presented in Table 3.

Table 3 indicates that although the a priori model with the six factors as proposed by Ryff (1989b) was noticeably better fitting compared to the one-factor model, the EFA model and the suggested six-factor second-order model, the goodness-of-fit statistics were moderate to poor. Table 3 further shows that the model with the two method factors produced the best fit in comparison to the other models, although the goodness-of-fit statistics were still not acceptable.

\section{Discussion}

A society that is characterised by innovation and enlightenment will also be a society in which most of the people in the society are afforded the opportunity to grow and develop as persons (Ryff, 2013a). The realising of one's true potential and consequently the highest of all human good, have been Aristotle's conception of eudaimonia (Ryff \& Singer, 1998). Psychological research that approaches well-being from this eudaimonic tradition has typically focussed on identifying the various factors that help people grow and develop to their fullest (Steger et al., 2008). Based on this tradition, Ryff (1989c) developed a model and measuring instrument that consist of six core psychological well-being dimensions. Although Ryff and Singer (2006) provided evidence to support the dimensionality of psychological well-being as set out in the RPWB scale, contradictory findings still appear in the literature. As such, the present study aimed to examine the factor structure of the RPWB scale in a South African sample in order to add to the international body of knowledge regarding eudaimonic wellbeing as measured by the RPWB scale.

The present study made use of the larger 84-item version of the RPWB, and therefore, an initial EFA was conducted to determine the number of factors to extract and 'to remove less important items, or items that are related to more than one factor' as suggested by Burns and Machin (2009, p. 371). The EFA of the RPWB produced a well represented and reliable five-factor solution with only 11 items excluded because of weak or double-factor loadings. The differing factor structure correlates with findings across various studies where different factor structures have been reported in the literature: Burns and Machin (2009) reported three factors, namely autonomy, positive relations and the EGPS factor; Vazi et al. (2013) also reported three factors but these factors were labelled positive self-evaluation, sense of contentment and sense of competence; finally, Kafka and Kozma (2001) initially found a 15-factor unrestricted solution, and then restrained it to six factors.

In the factor solution for this study, the first factor, general psychological well-being, consists of all the remaining positively worded RPWB items with four negatively worded items that needed to be reverse scored. This factor relates to a person's stance on having positive relations with others, being autonomous, having empathy, pursuing personal growth, having purpose in life and exhibiting self-acceptance. The remainder of the negatively worded items clustered together in four separate factors: interpersonal dependence (a person seemingly cannot make decisions on his or her own and is overly influenced by those around him or her, constantly worrying what others think of him or her), obstinate (someone who does not enjoy trying new ways of doing things and is fairly set in his or her ways), sense of loneliness (the feeling that one lacks close relations with others) and low motivation (an individual who seems to be indecisive about his or her future, questions the meaning of life in general and may feel insecure). 
The results of the CFA showed that the preferred model within a South African sample is the two-factor model where the positively worded items are grouped together in one factor and negatively worded items are grouped together in the second factor. Second to this, the a priori model with the six factors proposed by Ryff (1989b) was noticeably a better fitting model when compared to the remainder of the observed models. Villar, Triadó, Celdrán and Solé (2010) conducted an EFA on the 54-item version of the RPWB scales and the results produced a four-factor structure where one of the factors consisted mainly of negatively phrased items. Additionally, a few studies either tested a two-factor model in which positive and negative items clustered together or included both positive and negative method factors (Abbott et al., 2010; Burns \& Machin, 2009; Springer \& Hauser, 2006; Van Dierendonck et al., 2008). In all these studies, the impact of the negatively and positively phrased items of the RPWB was evident because the positively and negatively phrased items produced better fit when compared to the a priori model. Ryff and Keyes (1995) explained that the differentiation of items between positive and negative factors suggests that participants encounter agreement-disagreement bias when answering the questions: participants will tend to agree with all the positively phrased items while disagreeing with all the negatively worded items. According to Marsh (1986), participants need to use doublenegative logic to give an honest answer to negatively phrased items; such double-negative logic necessitates a greater level of verbal reasoning than what would otherwise have been needed when answering positively worded items. Abbott $e t$ al. (2010) suggested that the item phrasing, response wording and response categories of psychological measuring instruments should ensure accurate scores on the relevant psychological construct.

\section{Limitations and recommendations}

A limitation of the present study is that the same sample was used to conduct the EFA and the CFA. Only a few studies used EFA on the longer version of the Ryff scale, and their results were for the most part problematic, as was in the present study. According to Watkins (1989), the use of EFA to compare results between different populations with the hope of replicating a proposed factor structure or model may not be ideal for, amongst other reasons, the indeterminacy of the common factor model causes various researchers to come to different conclusions using the same correlation matrix. Another possible limitation to the present study is the sample size. Anderson and Gerbing (1988) were of the opinion that for a solution with three or more indicators per factor, a sample size of 150 or more will be sufficient to obtain parameter estimates containing small enough standard errors that will still be of practical use, which equate to a 2:1 ratio. Bentler and Chou (1987) recommend that:

The ratio of sample size to number of free parameters may be able to go as low as 5:1 under normal and elliptical theory, especially when there are many indicators of latent variables and the associated factor loadings are large. Although [if] there is even less experience on which to base a recommendation, a ratio of at least 10:1 may be more appropriate for arbitrary distributions. (p. 91)
In the present study, the ratio of sample size to the number of free parameters is approximately $6: 1$, which may be a little bit less ideal to obtain 'correct model evaluation chi-square probabilities' (Bentler \& Chou, 1987, p.91). The characteristics of the data in terms of race can be seen both as a limitation and an advantage. It is an advantage because the impact of race on the design was minimised; but given the fact that South Africa is a multicultural country, the sample appears to be a limitation with regards to generalisation to other cultures within South Africa. It would be interesting to include additional measures to determine the uniqueness of the lives of the various samples that have been investigated, such as financial status, physical well-being, daily responsibilities, etc., and relate these factors to the samples' psychological well-being.

Having an effective RPWB scale in South African could provide practitioners with a measure to monitor well-being amongst employees in the workplace. Since Ryff's six-factor model could not be replicated, the RPWB should be utilised with caution. However, it can still provide employers with valuable information that can aid in the development of wellbeing interventions and possibly in future studies evaluating these interventions.

\section{Conclusion and practical implications}

The analysis of the psychometric properties of the RPWB using EFA and CFA suggests that the negatively and positively worded items influence the functioning of the scale. The usefulness of including negatively worded items in the RPWB should be considered carefully (Sliter \& Zickar, 2014). Scale items should be easy to understand and interpret and not 'cognitively complex' (Hodge \& Gillepsie, 2003, p. 45). This is especially important in a multilingual and multicultural society such as South Africa. One alternative to negatively worded items is 'mixed response options' (all items worded in the same direction, but with mixed response options) (Barnette, 2000, p. 369). In this way, response bias can still be detected without forfeiting scale reliability. Hodge and Gillepsie (2003) proposed phrase completion as an alternative to mixing positively and negatively worded items.

The factor structure of the RPWB remains inconclusive and the scale should therefore be used with caution. More studies are required to produce a valid and reliable instrument that can measure psychological well-being in a multicultural South African society.

\section{Acknowledgements Competing interests}

The authors declare that they have no financial or personal relationships which may have inappropriately influenced them in writing this article.

\section{Authors' contributions}

C.M.H. was responsible for the data collection and writing of the article and assisted with the interpretation of the data. 
C.H. was the project leader responsible for conceptualising the study and analysing and interpreting the data and was also responsible for writing the article. L.I.J. assisted with the data collection and writing the article.

\section{References}

Abbott, R.A., Ploubidis, G.B., Huppert, F.A., Kuh, D., \& Croudace, T.J. (2010) An evaluation of the precision of measurement of Ryff's Psychological Well-being scales in a population sample. Social Indicators Research, 97(3), 357-373. http://dx.doi.org/10.1007/s11205-009-9506-x

Abbott, R.A., Ploubidis, G.B., Huppert, F.A., Kuh, D., Wadsworth, M.E.J., \& Croudace, T.J. (2006). Psychometric evaluation of predictive validity of Ryff's psychological well-being items in a UK birth cohort sample of women. Health and Quality of Life Outcomes, 4(76), 1-16. http://dx.doi.org/10.1186/1477-7525-4-76

Anderson, J.C., \& Gerbing, D.W. (1988). Structural equation modelling in practice: A review and recommended two-step approach. Psychological Bulletin, 103, 411-423. http://dx.doi.org/10.1037//0033-2909.103.3.411

Augusto-Landa, J.M., Pulido-Martos, M., \& Lopez-Zafra, E. (2011). Does perceived emotional intelligence and optimism/pessimism predict psychological wellbeing? Journal of Happiness Studies, 12(3), 463-474. http://dx.doi.org/10.1007/ s10902-010-9209-7

Barnette, J.J. (2000). Effects of stem and Likert response option reversals on survey internal consistency: If you feel the need, there is a better alternative to using those negatively worded stems. Educational and Psychological Measurement, 60(3), 361-370. http://dx.doi.org/10.1177/00131640021970592

Bentler, P.M., \& Chou, C.P. (1987). Practical issues in structural modeling. Sociological Methods\&Research,16,78-117.http://dx.doi.org/10.1177/0049124187016001004

Boehm, J.K., \& Kubzansky, L.D. (2012). The heart's content: The association between positive psychological well-being and cardiovascular health. Psychological Bulletin, 138(4), 655-691. http://dx.doi.org/10.1037/a0027448

Boers, M. (2014). Empirical evaluation of the Steyn-Boers structural model of psychological well-being at work. Unpublished master's dissertation, Stellenbosch University, Stellenbosch, South Africa.

Botha, E.M. (2006). Psychological well-being and biological correlates in African women. Unpublished doctoral thesis, North-West University, Potchefstroom Campus, Potchefstroom, South Africa.

Brown, T. (2006). Confirmatory factor analysis for applied research. New York, NY: Guilford Press.

Burns, R.A., \& Machin, A. (2009). Investigating the structural validity of Ryff's psychological well-being scales across two samples. Social Indicators Research, 93(2), 359-375. http://dx.doi.org/10.1007/s11205-008-9329-1

Cheng, S., \& Chan, A.C.M. (2005). Measuring psychological well-being in the Chinese. Personality and Individual Differences, 38, 1307-1316. http://dx.doi. org/10.1016/j.paid.2004.08.013

Clark, L.A., \& Watson, D. (1995). Constructing validity: Basic issues in scale development. Psychological Assessment, 7, 309-319. http://dx.doi. org/10.1037//1040-3590.7.3.309

Clarke, P.J., Marshall, V.W., Ryff, C.D., \& Wheaton, B. (2001). Measuring psychological well-being in the Canadian study of health and aging. International Psychogeriatrics, 13, 79-90. http://dx.doi.org/10.1017/s1041610202008013

Davidson, D. (2006). Psychological, physical and social wellbeing in an individual and team sport: A phenomenological and quantitative study. Unpublished master's dissertation, University of Zululand, Mhlathuze, South Africa.

De Chavez, A.C., Backett-Milburn, K., Parry, O., \& Platt, S. (2005). Understanding and researching wellbeing: Its usage in different disciplines and potential for health research and health promotion. Health Education Journal, 64(1), 70-87. http://dx.doi.org/10.1177/001789690506400108

Deci, E.L., \& Ryan, R.M. (2008). Hedonia, eudaimonia, and well-being: An introduction Journal of Happiness Studies, 9, 1-11. http://dx.doi.org/10.1007/s10902-0069018-1

Diener, E., Kesebir, P., \& Lucas, R. (2008). Benefits of accounts of well-being: For societies and for psychological science. Applied Psychology, 57(s1), 37-53. http:// dx.doi.org/10.1111/j.1464-0597.2008.00353.x

Dodge, R., Daly, A.P., Huyton, J., \& Sanders, L.D. (2012). The challenge of defining well-being. Journal of Wellbeing, 2(3), 222-235. http://dx.doi.org/10.5502/ijw. v2i3.4

Edwards, D.J., \& Edwards, S.D. (2012). The evaluation of a psychological skills training programme for rugby players. African Journal for Physical, Health Education, Recreation and Dance, 18(3), 525-534.

Erhabor, I.S., \& Ndlovu, N.D. (2013). How happy are married people? Psychological indicators of marital satisfaction of married men and women in Gauteng province, South Africa. Gender \& Behaviour, 11(2), 5486-5498.

Fava, G.A., \& Tomba, E. (2009). Increasing psychological well-being and resilience by psychotherapeutic methods. Journal of Personality, 77(6), 1903-1934. http://dx.doi.org/10.1111/j.1467-6494.2009.00604.x

Fernandes, H.M., Vasconcelos-Raposo, J., \& Teixeira, C.M. (2010). Preliminary analysis of the psychometric properties of Ryff's Scales of Psychological Well-Being in Portuguese adolescents. The Spanish Journal of Psychology, 13(2), 1032-1043. http://dx.doi.org/10.1017/s1138741600002675
Field, A. (2005). Discovering statistics using SPSS. (3rd edn.). London, UK: Sage.

Hamaker, E.L., Nesselroade, J.R., \& Molenaar, P.C.M. (2007). The integrated trait-state model. Journal of Research in Personality, 41, 295-315. http://dx.doi. org/10.1016/j.jrp.2006.04.003

Henn, C.M. (2013). Measures of well-being. In C. Foxcroft \& G. Roodt (Eds.), Introduction to psychological assessment in the South African context, (4th edn. pp. 171-184). Cape Town, South Africa: Oxford University Press.

Henson, R.K., \& Roberts, J.K. (2006). Use of exploratory factor analysis in published research: Common errors and some comment on improved practice. Educational and Psychological Measurement, 66(3), 393-416. http://dx.doi. org/10.1177/0013164405282485

Hodge, D.R., \& Gillepsie, D. (2003). Phrase completions: An alternative to Likert scales. Social Work Research, 27(1), 45-55. http://dx.doi.org/10.1093/swr/27.1.45

Huta, V., \& Waterman, A.S. (2014). Eudaimonia and its distinction from hedonia: Developing a classification and terminology for understanding conceptual and operational definitions. Journal of Happiness Studies, 15(6), 1425-1456. operational definitions. Journal of Happiness
$\mathrm{http} / / / \mathrm{dx}$.doi.org/10.1007/s10902-013-9485-0

IBM Corp. (Released 2013). IBM SPSS Statistics for Windows, Version 22.0 [Computer software]. Armonk, NY: IBM Corp.

Jones, N.L.K. (2014). Personality and job satisfaction: The moderating effect of psychological well-being. Unpublished master's dissertation, University of Johannesburg, Johannesburg, South Africa.

Kafka, G.J., \& Kozma, A. (2002). The construct validity of Ryff's scales of psychologica well-being (SPWB) and their relationship to measures of subjective well-being. Social Indicators Research, 57(2), 171-190.

Kállay, É., \& Rus, C. (2014). Psychometric properties of the 44-item version of Ryff's Psychological Well-Being Scale. European Journal of Psychological Assessment, 30(1), 15-21. http://dx.doi.org/10.1027/1015-5759/a000163

Kashdan, T.B., Biswas-Diener, R., \& King, L.A. (2008). Reconsidering happiness: The costs of distinguishing between hedonics and eudaimonia. The Journal of Positive Psychology, 3(4), 219-233. http://dx.doi.org/10.1080/17439760802303044

Kitamura, T., Yasuko, K., Gatayama, R., Matsuoka, T., Miura, S., \& Yamaba, K. (2004). Ryff's Psychological Well-Being Inventory: Factorial structure and life history correlates among Japanese university students. Psychological Reports, 94, 83-103. http://dx.doi.org/10.2466/pr0.94.1.83-103

Kitayama, S., Karasawa, M., Curhan, K.B., Ryff, C.D., \& Markus, H.R. (2010). Independence and interdependence predict health and wellbeing: Divergent patterns in the United States and Japan. Frontiers in Psychology, 1, 163. patterns in the United States and Japan.
$\mathrm{http}: / / \mathrm{dx}$.doi.org/10.1037/0012-1649.22.1.37

Lindfors, P., Berntsson, L., \& Lundberg, U. (2006). Factor structure of Ryff's Psychological Well-Being Scales in Swedish female and male white-collar workers. Personality and Individual Differences, 40, 1213-1222. http://dx.doi. Personality and Individual
org/10.1016/j.paid.2005.10.016

Marsh, H.W. (1986). Negative item bias in ratings scales for preadolescent children: A cognitive-developmental phenomenon. Developmental Psychology, 22, 37-49. $\mathrm{http}: / / \mathrm{dx}$.doi.org/10.1037/0012-1649.22.1.37

Nelson, D.L., \& Simmons, B.L. (2003). Health psychology and work stress: A more positive approach. In J.C. Quick \& L.E. Tetrick (Eds.), Handbook of occupational psychology, (pp. 97-119). Washington, DC: American Psychological Society.

Pallant, J. (2011). SPSS survival manual: A step by step guide to data analysis using SPSS program. (5th edn.). Maidenhead, United Kingdom: McGraw Hill.

Roodt, G. (1991). Die graad van werkbetrokkenheid as voorspeller van persoonlike welsyn: 'n studie by bestuurders. [The degree of work involvement as a predictor of personal well-being: A study among managers]. Unpublished doctoral thesis, University of the Orange Free State, Bloemfontein, South Africa.

Ryan, R.M., \& Deci, E.L. (2001). On happiness and human potentials: A review of research on hedonic and eudaimonic well-being. Annual Review of Psychology, 52(1), 141-166. http://dx.doi.org/10.1146/annurev.psych.52.1.141

Ryff, C.D. (1989a). Beyond Ponce de Leon and life satisfaction: New directions in quest of successful aging. International Journal of Behavioural Development, 12(1), 35-55. http://dx.doi.org/10.1177/016502548901200102

Ryff, C.D. (1989b). In the eye of the beholder: Views of psychological well- being among middle-aged and older adults. Psychology and Aging, 4, 195-210. among middle-aged and older adults. Psycho
http://dx.doi.org/10.1037/0882-7974.4.2.195

Ryff, C.D. (1989c). Happiness is everything, or is it? Explorations on the meaning of psychological well-being. Journal of Personality and Social Psychology, 57, 1069-1081. http://dx.doi.org/10.1037/0022-3514.57.6.1069

Ryff, C.D. (2013a). Eudaimonic well-being and health: Mapping consequences of selfrealization. In A.S. Waterman (Ed.), The best within us: Positive psychology perspectives on eudaimonia, (pp. 77-98). Washington, DC: American Psychological Association.

Ryff, C.D. (2013b). Psychological well-being revisited: Advances in the science and practice of eudaimonia. Psychotherapy and Psychosomatics, 83(1), 10-28. http://dx.doi.org/10.1159/000353263

Ryff, C.D., Dienberg, L.G., Urry, H.L., Muller, D., Rosenkranz, M.A., Friedman, E.M., et al. (2006). Psychological well-being and ill-being: Do they have distinct or mirrored biological correlates? Psychotherapy and Psychosomatics, 75(2), 85-95. http://dx.doi.org/10.1159/000090892

Ryff, C.D., \& Keyes, C.L.M. (1995). The structure of psychological well-being revisited. Journal of Personality and Social Psychology, 69(4), 719. http://dx.doi. org/10.1037/0022-3514.69.4.719

Ryff, C.D., Magee, W.J., Kling, K.C., \& Wing, E.H. (1999). Forging macro-micro linkages in the study of psychological well-being. In C.D. Ryff \& V.M. Marshall (Eds.), The self and society in aging processes, (pp. 247-278). New York: Springer. 
Ryff, C.D., \& Singer, B. (1998). The contours of positive human health. Psychological Inquiry, 9(1), 1-28. http://dx.doi.org/10.1207/s15327965pli0901_1

Ryff, C.D., \& Singer, B.H. (2006). Best news yet on the six factor model of well-being Social Science Research, 35, 1103-1119. http://dx.doi.org/10.1016/j. ssresearch.2006.01.002

Ryff, C.D., \& Singer, B.H. (2008). Know thyself and become what you are: A eudaimonic approach to psychological well-being. Journal of Happiness Studies, 9(1), 13-39. http://dx.doi.org/10.1007/s10902-006-9019-0

Sirigatti, S., Penzo, I., Iani, L., Mazzeschi, A., Hatalskaja, H., Giannetti, E., et al. (2013). Measurement invariance of Ryff's Psychological Well-being Scales across Italian and Belarusian students. Social Indicators Research, 113, 67-80. http://dx.doi. org/10.1007/s11205-012-0082-0

Sirigatti, S., Stefanile, C., Giannetti, E., Iani, L., Penzo, I., \& Mazzeschi, A. (2009) Assessment of factor structure of Ryff's Psychological Well-Being Scales in Italian adolescents. Bollettino di Psicologia Applicata, 259, 30-50.

Sliter, K.A., \& Zickar, M.J. (2014). An IRT examination of the psychometric functioning of negatively worded personality itens. Educational and Psychologica

Measurement, 74(2), 214-226. http://dx.dol.org/10.1177/0013164413504

Springer, K.W., \& Hauser, R.M. (2006). An assessment of the construct validity of Ryff's Scales of Psychological Well-being: Method, mode and measurement effects.
Social Science Research, 35, 1080-1102. http://dx.doi.org/10.1016/j. ssresearch.2005.07.004

Springer, K.W., Hauser, R.M., \& Freese, J. (2006). Bad news indeed for Ryff's six factor model of well-being. Social Science Research, 35, 1120-1131. http://dx.doi. org/10.1016/j.ssresearch.2006.01.003

Steger, M.F., Kashdan, T.B., \& Oishi, S. (2008). Being good by doing good: Daily $\mathrm{http}: / / \mathrm{dx}$.doi.org/10.1016/j.jrp.2007.03.004

Steyn, B.J.M., \& Roux, S. (2009). Aggression and psychological well-being of adolescent Tae Kwon Do participants in comparison with hockey participants and a non-sport group. African Journal for Physical, Health Education, Recreation and Dance, 15(1), 32-43. http://dx.doi.org/10.4314/ajpherd.v15i1.44636

Triadó, C., Villar, F., Solé, C., \& Celdrán, M. (2007). Construct validity of Ryff's Scale of Psychological Well-Being in Spanish older adults. Psychological Reports, 100, 1151-1164. http://dx.doi.org/10.2466/PR0.100.4.1151-1164
Van Dierendonck, D. (2004). The construct validity of Ryff's Scales of Psychological Well-Being and its extension with spiritual well-being. Personality and Individual Differences, 36, 629-643. http://dx.doi.org/10.1016/S01918869(03)00122-3

Van Dierendonck, D., Díaz, D., Rodríguez-Carvajal, R., Blanco, A., \& Moreno-Jiménez, B. (2008). Ryff's six-factor model of psychological well-being, a Spanish exploration. Social Indicators Research, 87(3), 473-479. http://dx.doi. org/10.1007/s11205-007-9174-7

Van Schalkwyk, I., \& Wissing, M.P. (2010). Psychosocial well-being in a group of South African adolescents. Journal of Psychology in Africa, 20(1), 53-60.

Vazi, M.L.M., Ruiter, R.A.C., van den Borne, B., Martin, G., Dumont, K., \& Reddy, P.S (2013). The relationship between wellbeing indicators and teacher psychological stress in Eastern Cape public schools in South Africa. SA Journal of Industrial Psychology, 39(1), Art. \#1042, 10 pages. http://dx.doi.org/10.4102/sajip. v39i1.1042

Vercueil, A.C. (2010). The effect of the Tomatis Method on the psychological well-being and piano performance of student pianists. Unpublished doctoral thesis, North-West University, Potchefstroom Campus, Potchefstroom, South Africa.

Victor, K. (2013). Psychological wellbeing, religiousness and spirituality in the lives of adolescents from intact and divorced families. Unpublished master's dissertation, Stellenbosch University, Stellenbosch, South Africa.

Villar, F., Triadó, C., Celdrán, M., \& Solé, C. (2010). Measuring well-being among Spanish older adults: Development of a simplified version of Ryff's Scales of Psychological Well-Being. Psychological Reports, 107, 265-280. http://dx.doi. org/10.2466/02.07.08.10.21.PRO.107.4.265-280

Waterman, A. (2008). Reconsidering happiness: A eudaimonist's perspective. The Journal of Positive Psychology, 3(4), 234-252. http://dx.doi.org/10.1080/17439760 802303002

Watkins, D. (1989). The role of confirmatory factor analysis in cross-cultural research. International Journal of Psychology, 24, 685-701.

Williams, B., Brown, T., \& Onsman, A. (2010). Exploratory factor analysis: A five-step guide for novices. Australasian Journal of Paramedicine, 8(3), 1-14. 